\title{
The Effect of Polypyrrole and Nickel + Polypyrrole Coatings on Corrosion Behaviour AISI 304 Stainless Steel ${ }^{1}$
}

\author{
A. Buyuksagis ${ }^{a}$, S. Kara ${ }^{b}$, and A. A. Aksut ${ }^{c}$ \\ ${ }^{a}$ Afyon Kocatepe University, Science and Literature Faculty, Afyonkarahisar, Turkey \\ ${ }^{b}$ Murefte Cok Programli Lisesi, Tekirdag, Turkey \\ ${ }^{c}$ Ankara University, Science Faculty, Ankara, Turkey \\ e-mail:absagis@aku.edu.tr \\ Received December 05, 2013
}

\begin{abstract}
Polypyrrole (PPy) and nickel + PPy (Ni + PPy) coatings have been occured on AISI 304 stainless steel (304 SS) surface by cyclic voltammetry technique in aqueous oxalic acid solutions and as the supporting electrolytes was used saccharin and $\mathrm{NaNO}_{3}$. Corrosion behavior of the PPy and $\mathrm{Ni}+\mathrm{PPy}$ coated $304 \mathrm{SS}$ electrodes was investigated using linear anodic polarization, Tafel extrapolation and electrochemical impedance spectroscopy (EIS) techniques in various aqueous solutions. The polypyrrole coated samples were characterized by scanning electron microscope (SEM) and Fourier Transform Infrared spectroscopy (FTIR). SEM analysis showed that PPy structure depends closely on the electrochemical conditions. Additionally, it is seen from FTIR analysis, characteristic polypyrrole absorption bands have occurred in all the coated surfaces. Tafel analyses and open-circuit potential datas revealed that the PPy and $\mathrm{Ni}+\mathrm{PPy}$ coatings effectively protect the steel from corrosion in $\mathrm{H}_{2} \mathrm{SO}_{4}$ and $\mathrm{NaOH}$ solutions. However, the corrosion protection properties were reduced with immersion time. $\mathrm{Ni}+$ PPy coatings more effectively protects the steel from corrosion than polypyrrole
\end{abstract}

DOI: $10.1134 / \mathrm{S} 2070205115010025$

\section{INTRODUCTION}

Conductive polymers use in areas such as biosensors and gas sensors $\left(\mathrm{NO}_{2}, \mathrm{SO}_{2}\right.$ etc. $)$, catalysis, optics, capacitors, analog lithium batteries, telecomunications, molecular electronics, functional membranes, cables for transmission purposes, anti-electro static coatings (textiles) [1-11]. Polypyrrole obtained by electrochemical polymerization method have gained an important place in the field of developments of new sensors, drug delivery, measuring instruments [1214]. Rahman and Ba-Shammakh [15] achieved a very good compact and adhesive films in alkaline medium. Shao et al. [16] electrochemically synthesized polypyrrole on gold electrodes that was used as a support for fat two-layer membrane (BLMs). Martins et al. [17] conducted pyrrole electropolymerization on iron surfaces in aqueos malate solution and investigated effect of $\mathrm{pH}$ using different electrochemical techniques. Giacomini et al. [18] represented voltammetric measurements of electrochemically deposited polypyrrole film in possession of a wide range of colour change. Yagan et al. [19] obtained polyaniline (PANI) and polypyrrole (PPy) double coatings in aqueous oxalic acide solutions. All of PPy coatings showed the best corrosion resistance. Sabouri et al. [20] showed that PPy-tungstate coatings noticeably prevents corrosion. Aharzadeh et al. [21] showed that

\footnotetext{
${ }^{1}$ The article is published in the original.
}

in the presence of saccharin $E_{\text {corr }}$ potential values shifted to more noble values that results in better resistance against corrosion. In work of A. Ashrafi et al. [22] the electrochemical polymerization of pyrrole on stainless steel substrate was analyzed by means of rotating disc electrode method. As a result, depending on the deposition conditions were obtained semicrystalline, flat, semi-flat, island type such as a needle and tube in the form of spherical different surface morphologies. Gao et al. [23] obtained polypyrrolestructured microspheres synthesized by electrochemical method. Microspheres were synthesized on indium tin oxide (ITO) glass electrodes. Sphere density on surface was about 106 unit $\mathrm{cm}^{-2}$.

In this study PPy coatings have been electrodeposited on 304 SS surface by cyclic voltammetry technique in aqueous oxalic acid solutions and as the supporting electrolytes are used $0.5 \mathrm{~g} \mathrm{dm}^{-3}$ saccharin and $0.2 \mathrm{~mol} \mathrm{dm}^{-3} \mathrm{NaNO}_{3}$. Watts's bath was used as electrolyte and a standard DC power supply was used as a power source for Ni coatings. Corrosion behaviour of the PPy and Ni + PPy coated 304 SS electrodes was investigated using linear anodic polarization, Tafel extrapolation and EIS techniques in various aqueous corrosive solutions. The PPy coated samples have been characterized by SEM and FTIR. 


\section{EXPERIMENTAL}

\subsection{Electrodes and Chemical Reagents}

$304 \mathrm{SS}\left(0.2826 \mathrm{~cm}^{2}\right.$ apparent area) axially mounted in PTFE holders were used as working electrodes. It's chemical composition (wt \%) is: $18.45 \mathrm{Cr}, 8.36 \mathrm{Ni}$, $1.50 \mathrm{Mn}, 0.48 \mathrm{Mo}, 0.48 \mathrm{Si}, 0.08 \mathrm{C}, 0.02 \mathrm{P}, 0.29 \mathrm{~S}, 0.48$ $\mathrm{Cu}$ and Fe balance. $304 \mathrm{SS}$ were first cleaned mechanically with increasing grades of emery papers with grit size $120,400,600,800,1000$ and 1200 followed by a wash with $1 / 1(\mathrm{vol} / \mathrm{vol})$ acetone-alcohol mixture and bidistilled (at $30^{\circ} \mathrm{C}$ for $15 \mathrm{~min}$ ) water by using Bandelin ultrasonic bath. After then cleaning the surface specimens were dried at $40^{\circ} \mathrm{C}$ for $1 \mathrm{~h}$. The reference electrode was $\mathrm{Hg} / \mathrm{Hg}_{2} \mathrm{Cl}_{2}$ (sat. $\mathrm{KCl}$ ) and the counter electrode was a platinum sheet. In this study, all electrode potential values were referred to this reference electrode. All experiments were conducted at a constant temperature $\left(25^{\circ} \mathrm{C}\right)$ and in non-stirred solutions [24]. These electrodes were housed in jacketed cell that allows circulation of hot/cold water so that a desired temperature is maintained during the process of electrosynthesis [25]. Cleaned surface working electrode was immersed in experiment solution. Oxygen was removed by bubbling $\mathrm{N}_{2}$ gas for about $30 \mathrm{~min}$ through the solutions. PPy coated surface of electrode was occured by means of cyclic voltammetry. In experimental studies, pyrrole (Aldrich) distilled under vacuum was used. It is reserved nitrogen atmosphere in brown glass bottles $+4^{\circ} \mathrm{C}$ refrigerator for experimental studies. All the other chemicals were analytical grade from Merck and used as received. To obtain a better PPy coating it was added $0.5 \mathrm{~g} \mathrm{dm}^{-3}$ saccharin and $0.2 \mathrm{~mol} \mathrm{dm}^{-3} \mathrm{NaNO}_{3}$ as a supporting electrolyte (SE) in $0.3 \mathrm{~mol} \mathrm{dm}^{-3}$ oxalic acid $+0.1 \mathrm{~mol} \mathrm{dm}^{-3}$ pyrrole solution [21-23, 26, 27].

\subsection{Electrochemical Methods}

2.2.1. Nickel electrochemical deposition: Watts's bath was used as electrolyte and a standard DC power supply (SHENZEN MASTECH HY 3003-3 model) with variable potential was used as a power source. The properties of Watt's bath was $\mathrm{NiSO}_{4} \cdot 7 \mathrm{H}_{2} \mathrm{O}\left(300 \mathrm{~g} \mathrm{dm}^{-3}\right)$, $\mathrm{NiCl}_{2} \cdot 6 \mathrm{H}_{2} \mathrm{O}\left(60 \mathrm{~g} \mathrm{dm}^{-3}\right), \mathrm{H}_{3} \mathrm{BO}_{3}\left(30 \mathrm{~g} \mathrm{dm}^{-3}\right)$, current A ( $1 \mathrm{~V}) 0.02$, bath temperature $\left({ }^{\circ} \mathrm{C}\right) 60-80, \mathrm{pH} 4.5-$ 5.0. Ni anode used for the plating was taken as $2 \mathrm{~cm}^{2}$ surface areas (99.9\% purity) and all nickel plating was obtained under atmospheric condition. The distance between anode and cathode was kept constant at $20 \mathrm{~mm}$.

2.2.2. Cyclic voltammetry: Gamry reference 600 potentiostat/galvanostat/ZRA system (Gamry Inc., USA) was used for potential-controlled polarization measurements. This system was interfaced to a personal computer to control the experiments which were controlled and the data were analyzed by using a Gamry framework/Echem analysis software. 304 SS was kept in $1 \mathrm{~mol} \mathrm{dm}^{-3} \mathrm{NaOH}$ at $60^{\circ} \mathrm{C}$ for $4 \mathrm{~h}$ to ensure good adhesion to the surface of pyrrole before PPy and
Ni electrodeposition. Pyrrole was deposited on 304 SS at varying conditions, such as potential range, number of cycles, and the scanning rate. In order to obtain adherent, smooth, uniform and stable coatings, it was necessary to optimize electrodeposition conditions. For this purpose, polymerization condition was changed systematically.

For the evaluation of this effect, electrochemical deposition was carried out at the same conditions as above, but at various numbers of cycles. A linear relationship was observed between the number of cycle and the amount of PPy deposited on the electrode surface. However, in agreement with Joseph et al. [28], as the coating becomes thicker by using more cycles voltammograms (CV), the adhesion of the deposited film also decreases. A value of 10 was selected for the number of $\mathbf{C V}$ cycles for further experiments.

The current-potential curves were obtained for different scanning rates $\left(5,10,20,50,100 \mathrm{mV} \mathrm{s}^{-1}\right)$ for determine passivity range. Creating optimum conditions for PPy have been found at $25^{\circ} \mathrm{C}$ in $0.3 \mathrm{~mol} \mathrm{dm}^{-3}$ oxalic acid $+0.1 \mathrm{~mol} \mathrm{dm}^{-3}$ pyrrole $+\mathbf{S E}$ solutions at potential region between $0.3 \mathrm{~V}$ up to the $0.8 \mathrm{~V}, 20 \mathrm{mV} \mathrm{s}^{-1}$ scan rate and 10 cycles voltammograms. Experimental studies continuous in this way.

2.2.3. Tafel extrapolation and electrochemical impedance spectroscopy (EIS): Potentiodynamic current-potential curves of 304 SS were obtained in an aqueous solution and $1 \mathrm{mV} \mathrm{s}^{-1}$ scanning rate. EIS measurements were measured between $1 \times 10^{4}$ and $2 \times$ $10^{-1} \mathrm{~Hz}$ range with $10 \mathrm{mV}$ amplitude.

\subsection{Surface Characterization}

SEM micrographs took LEO 1430 VP SEM microscopy. The structural characterization of the PPy coating films was performed using a Perkin Elmer BX-II FTIR spectrophotometer with a resolution of $4 \mathrm{~cm}^{-1}$ in the absorbance mode.

\section{RESULTS AND DISCUSSIONS}

\subsection{Cyclic Voltammetry Results}

As the bare stainless steel was immersed in aerated solution containing $0.1 \mathrm{M}$ pyrrole, the potential of steel shifted to positive side and became spontaneously passive within few minutes. From this condition the electrodeposition of polypyrrole was carried out on the stainless steel surface as well as on platinum surface without any measurable induction period where the electrode potential soon reached a stable plateau. This is because the surface oxide film which formed spontaneously facilitated the electropolymerization by sup-pressing the substrate dissolution and the monomer oxidation occurs at once with applied anodic current.

Cyclic voltammetry method was used to form electrochemical PPy coating. Current-potential curves of Pt and $304 \mathrm{SS}$ electrodes obtained in $0.3 \mathrm{M}$ oxalic acid 
(a)

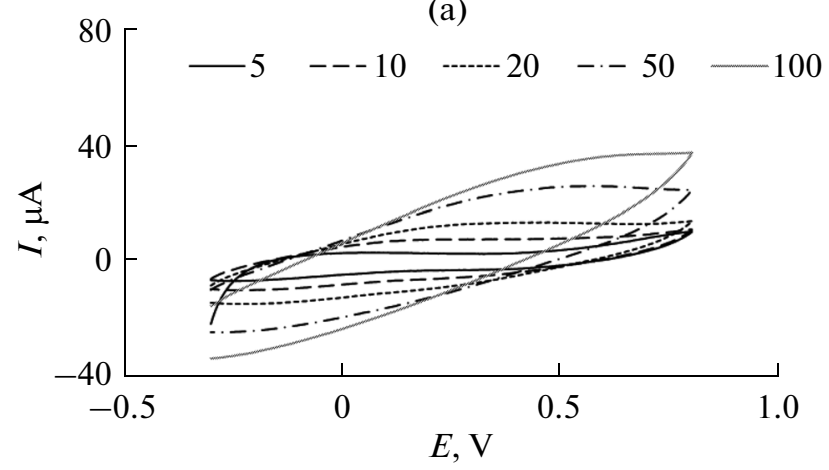

(c)

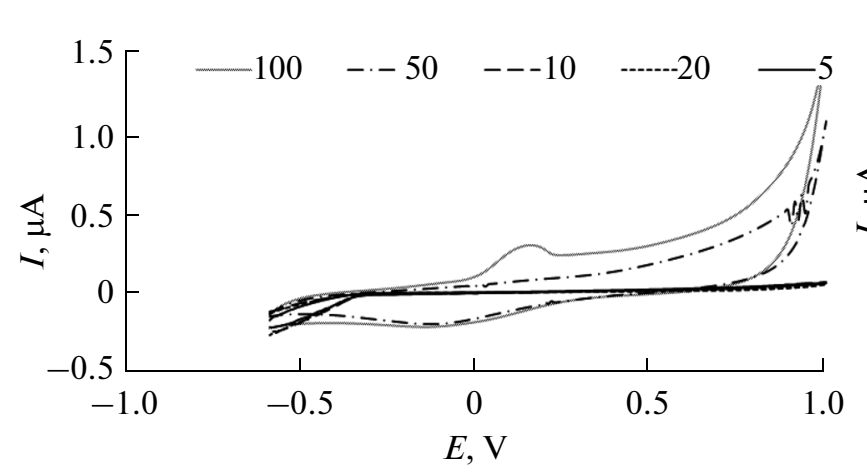

(b)

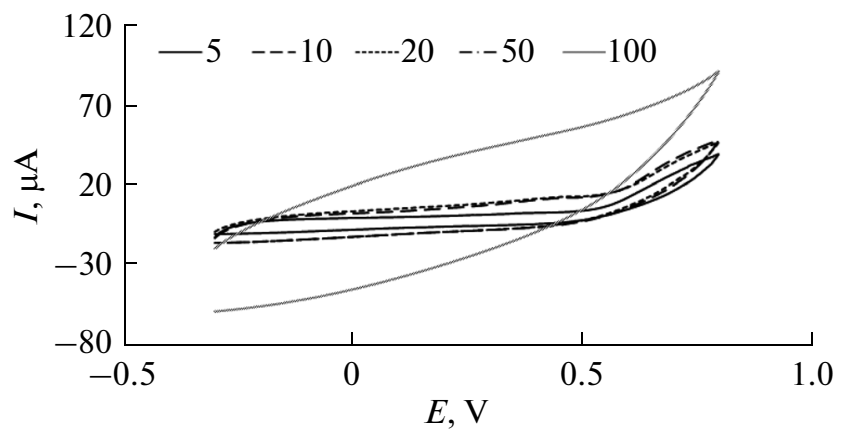

(d)

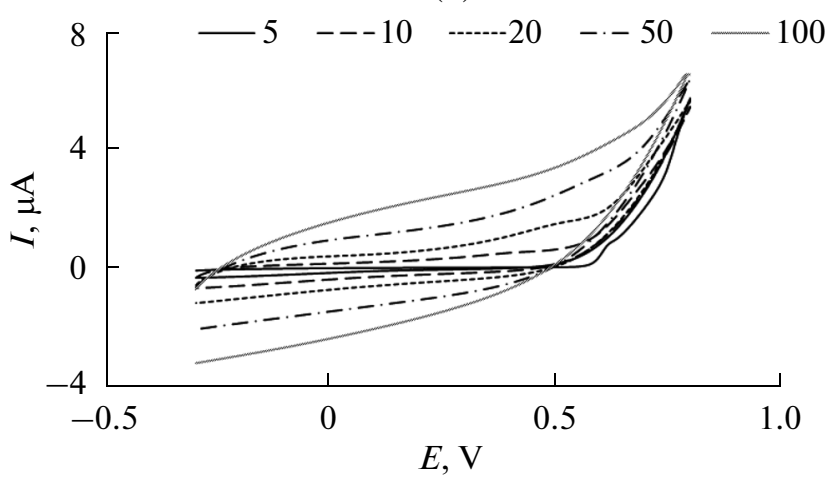

Fig. 1. Different scanning rate plots, (a) Platinum (in $0.3 \mathrm{~mol} \mathrm{dm}^{-3}$ oxalic acide). (b) Platinum (in $0.3 \mathrm{~mol} \mathrm{dm}^{-3} \mathrm{oxalic}^{-3}$ acide + $0.1 \mathrm{~mol} \mathrm{dm}^{-3}$ pirol $+\mathrm{SE}$ ) (c) $304 \mathrm{SS}$ (in $0.3 \mathrm{~mol} \mathrm{dm}^{-3}$ oxalic acide) d) $304 \mathrm{SS}$ (in $0.3 \mathrm{~mol} \mathrm{dm}^{-3}$ oxalic acide $+0.1 \mathrm{~mol} \mathrm{dm}^{-3} \mathrm{pirol}+\mathrm{SE}$ ).

and $0.3 \mathrm{M}$ oxalic acid $+0.1 \mathrm{M}$ pyrrole $+\mathbf{S E}$ solutions were displayed Fig. 1. In Fig. 1a almost at all scanning rate plots passivity potential region didn't observe. If scan rate increases, current values raise. According to Fig. $1 \mathrm{~b}$ between $-0.30 \mathrm{~V}$ and $+0.50 \mathrm{~V}$ potential range can be considered as passivity. The passivity range does not exist at $100 \mathrm{mV} \mathrm{s}^{-1}$ scan rate. In Fig. $1 \mathrm{c}$ scanning rate increases, current values in oxalic acid solution is also not increasing. Only $100 \mathrm{mV} \mathrm{s}^{-1}$ scan rate has an oxidation peak at the $0.15 \mathrm{~V}$. Passivity range is between $-0.4 \mathrm{~V}$ and $0.8 \mathrm{~V}$. Figure $1 \mathrm{~d}$ presents passivity range is between $-0.3 \mathrm{~V}$ and $+0.5 \mathrm{~V}$ potential, scanning rate $5 \mathrm{mV} \mathrm{s}^{-1}$.

PPy was obtained in the number of cycles of different scanning rates. The best scanning rate is determined as $20 \mathrm{mV} \mathrm{s}^{-1}$. In this scanning rate, cyclic voltamograms for $\mathrm{Pt}$ and $304 \mathrm{SS}$ in $0.3 \mathrm{M}$ oxalic acid and $0.3 \mathrm{M}$ oxalic acid + SE solutions presented in Fig. 2. Acidic media has been chosen in order to avoid formation of non-soluble corrosion products into the PPy pores and diffusion limitations of oxygen reduction as cathodic reaction in neutral solutions.

In Fig. 2a increasing current values after $0.5 \mathrm{~V}$ in acidic solution shown oxidation of oxalate. Adherent films of PPy and other conductive polymers have been demonstrated to raise the potential of steel in the passive region to provide anodic protection. The deposition competes with the dissolution of iron [25].
Whereas in the conducting polymer $(\mathbf{C P})$ containing coatings the main role played by a passivating oxide layer formed in the interface is one of the protection mechanisms proposed and being usually accepted (anodic protection). It was postulated that galvanic coupling of the polymer to the substrate should contribute to oxidize the substrate forming a passive film [29].

Increasing the number of cycles decreased the current values. Accumulation of electroactive material onto the surface of the electrode is determined increases during the anodic and cathodic currents. Peak area and current decreased with increasing number of cycles. Decreasing current density was interested in formation of PPy films and growth on the surface. In Fig. 2b current is close to be zero until $0.580 \mathrm{~V}$ potential (after 4th peak). It can be said that after 4th peak of current increase due to oxidation potential of pyrrole. Over time current drop, pyrrole monomer in the electrolyte solution formation of polymerized PPy film layer on the surface of Pt and shown oxygen output barrier property. At the Fig. 2c oxidation peaks observed at the first four cycles. Any reaction is not observed on the back cycles. Oxidation current peak isn't observe after 4th cycle. The surface of electrode is absolutely has closed. In low potential, current density of iron working electrode dissolution is increased. Electrolytic solution turns slightly yellow. Three area were seen at the dissolution of iron. First area the cor- 

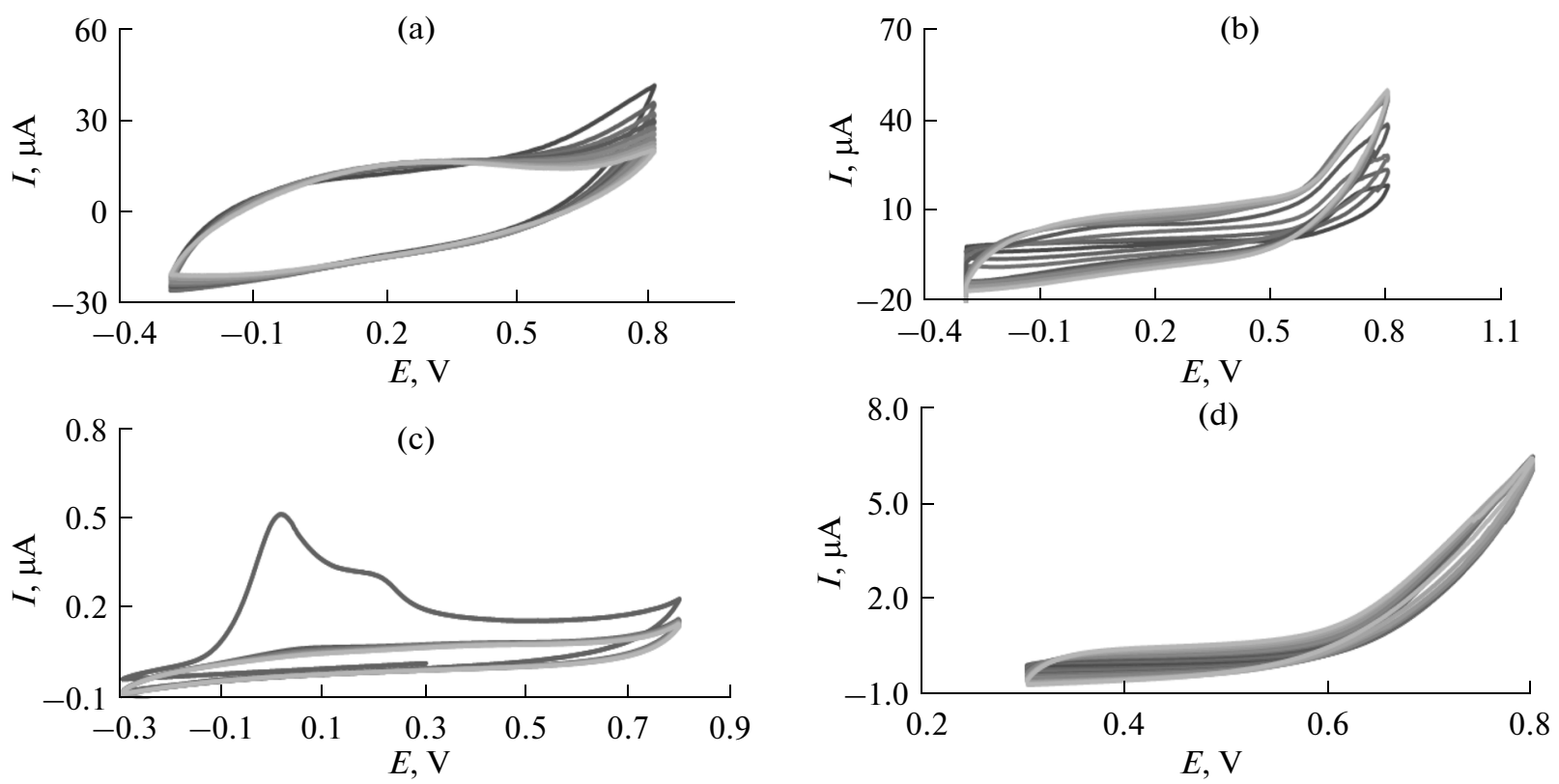

Fig. 2. Cyclic voltammograms for Pt and $304\left(20 \mathrm{mV} \mathrm{s}^{-1}, 10\right.$ cycles). (a) Platinum (in $0.3 \mathrm{~mol} \mathrm{dm}^{-3}$ oxalic acide), (b) Platinum (in $0.3 \mathrm{~mol} \mathrm{dm}^{-3}$ oxalic acide $+0.1 \mathrm{~mol} \mathrm{dm}^{-3}$ pirol $+\mathrm{SE}$ ) (c) $304 \mathrm{SS}$ (in $0.3 \mathrm{~mol} \mathrm{dm}^{-3}$ oxalic acide) (d) $304 \mathrm{SS}$ (in $0.3 \mathrm{~mol} \mathrm{dm}^{-3}$ oxalic acide $+0.1 \mathrm{~mol} \mathrm{dm}^{-3}$ pirol $+\mathrm{SE}$ ).

rosion rate of the anodic current density calculated from the regions high and increases the potential for an active area. Second area is passivity zone, current density decreases. According to 1 reaction

$$
\mathrm{Fe}^{2+}+\mathrm{C}_{4} \mathrm{H}_{4} \mathrm{O}_{6}^{2-}=\mathrm{FeC}_{4} \mathrm{H}_{4} \mathrm{O}_{6}
$$

The corrosion product seems to be $\mathrm{FeO}$ (black colour), which later converts into $\mathrm{Fe}_{2} \mathrm{O}_{3}$ (reddish rust) or $\mathrm{Fe}_{3} \mathrm{O}_{4}$ (black colour and metallic shine). Indeed, the variety of colors in the scribe and in the surrounding area suggests the apparition of hydrated or hydroxide iron oxides, like goethite, lepidocroyde or others $\left(\mathrm{Fe}(\mathrm{OH})_{3}, \mathrm{FeO} \cdot \mathrm{OH} \cdot n \mathrm{H}_{2} \mathrm{O}\right)$ [30], a passive layer occurs. The passive film is more stable and corrosion rate decreases. $3^{\text {rd }}$ region where the potential is higher than $1.2 \mathrm{~V}$. Passive film is broken, corrosion rate increases the transpassive area. The breaking passivity is close the potential for the formation of oxygen. In oxalic acid solutions, inner polymer layers are modified electrode surface condition [31]. Current peak relates to the $\mathrm{Fe}$ (III) formation. Figure $2 \mathrm{~d}$ shows passivity range can acceptable between $0.3 \mathrm{~V}$ to $0.6 \mathrm{~V}$ potential. Current values didn't increase with increasing number of cycles. There is the formation of polypyrrole on the surface [32, 33].

Galvanic interaction between the metallic substrate and the coating is the most postulated reason for corrosion protection imparted by conducting polymers [31]. The polymer has the ability to oxidize the metal to form a passive film [33]. This and other proposed mechanisms to be operative require the coating to be in the conductive state [5].
A single layer on the electrode for the formation of a passive film may be a result of saccharin adsorption. A thin PPy coating on the surface consisted of from the first cycle. This film has catalytic effect on the electropolymerization reaction. The PPy films are not homogenous and has low adhesion. This behaviour can occur on the surface electrochemical reaction at the same time competitive hydroxides which merged with the film. Good adhesion on surface of the polymer film depends on interaction between the metallic surface and the inner surface. Therefore electropolymerization plays a major role in developing a passive film on the surface [17]. The oxidized and reduced state of the PPy polymer involves the n-electron system in the aromatic ring and movements of the doping anions in and out of the film. During the polarization curves, these redox processes produce an additional current to the current due to the oxidation and reduction of the stainless steel substrate and need to be determined to find out the true currents of the 304 SS substrate. Although the redox properties of the polymer depend on factors such as composition of the electrolyte, electrode potential and the substrate. The assumption was made on the basis that the polymer was created in the same conditions and that the current in the platinum electrode does not show any appreciable redox process in the $\mathrm{NaCl}$ electrolyte at the concentrations and range of potentials used [29]. 
(a)
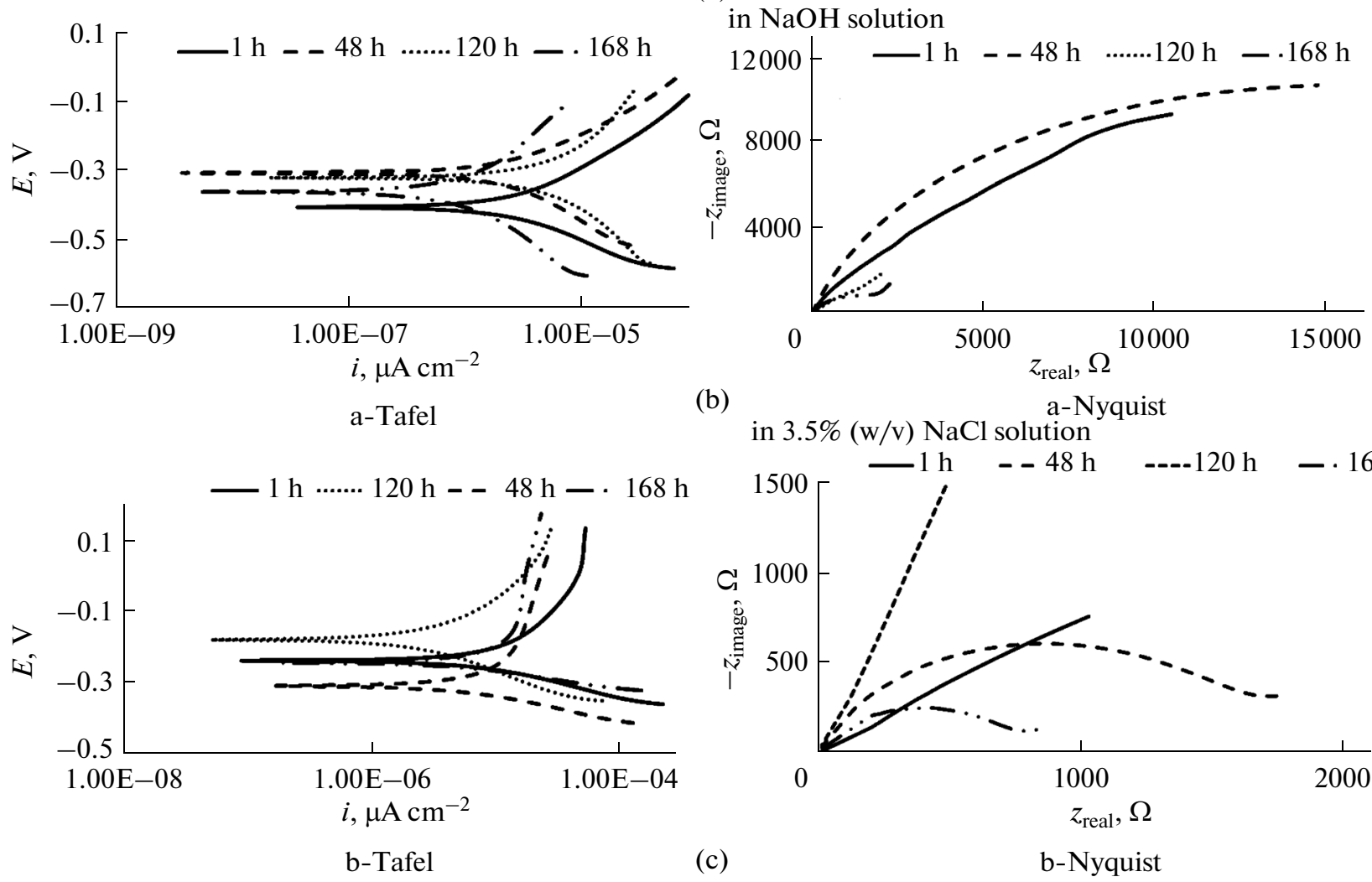

(b)
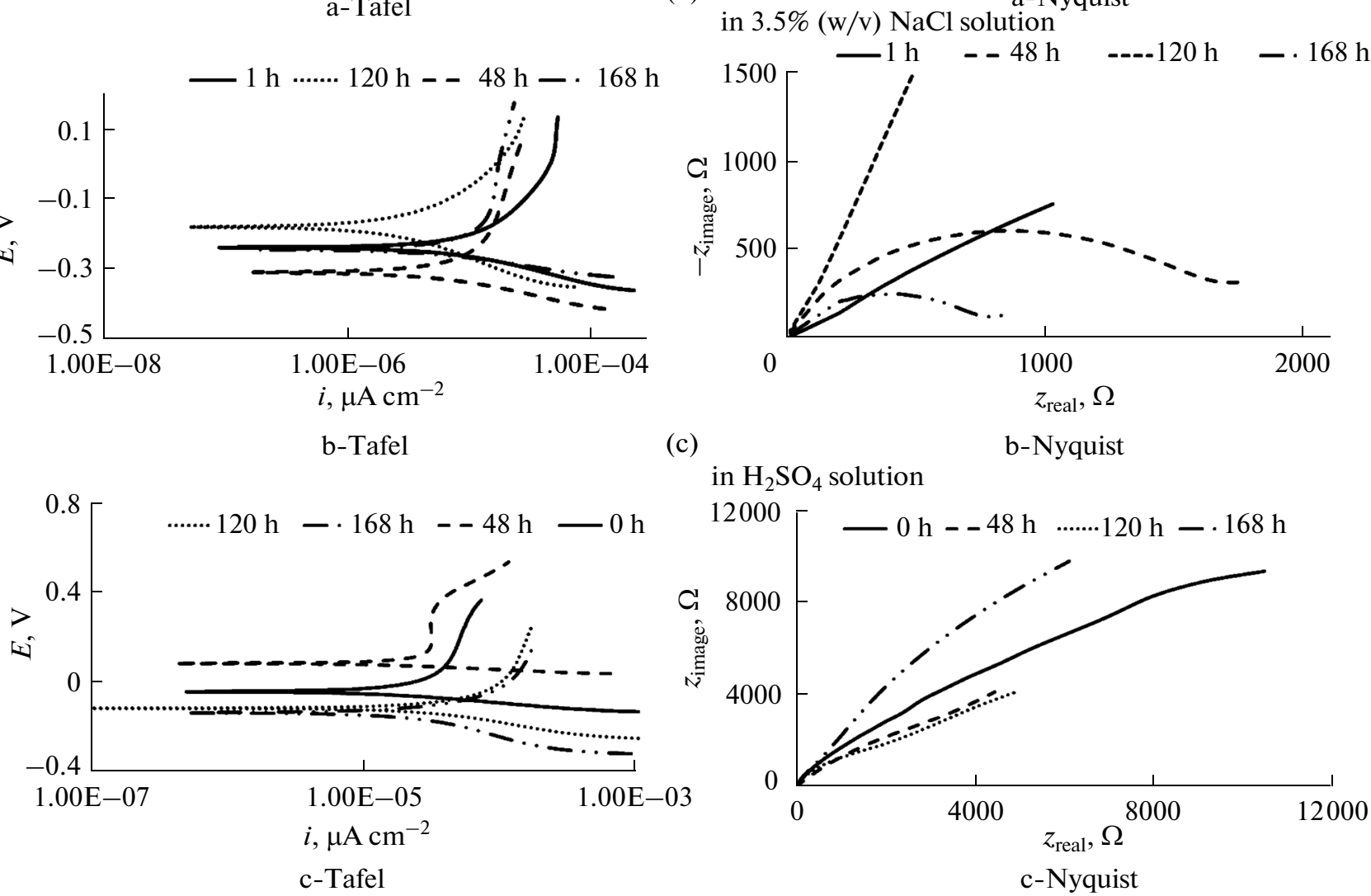

(c)

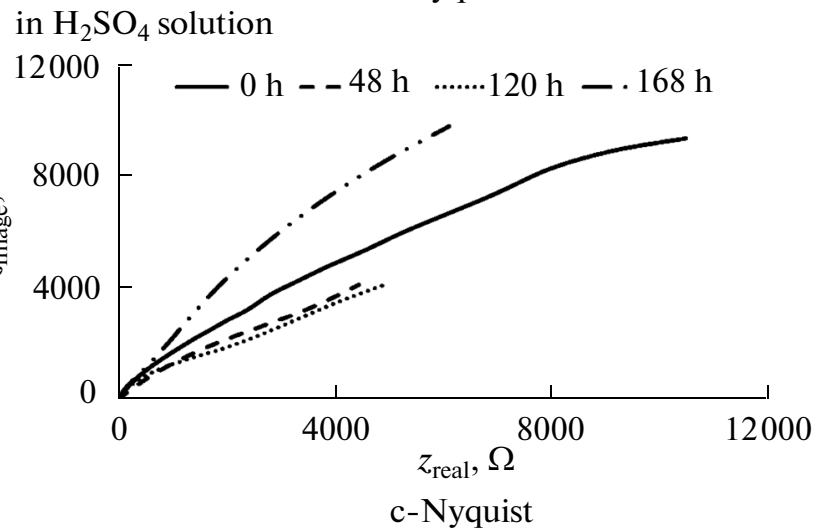

Fig. 3. Tafel and Nyquist plots of PPy coated $304 \mathrm{SS}$ in $1 \mathrm{~mol} \mathrm{dm}^{-3} \mathrm{NaOH}, 0.5 \mathrm{~mol} \mathrm{dm}^{-3} \mathrm{H}_{2} \mathrm{SO}_{4}$ and $3.5 \%$ (wt/vol) NaCl solutions different immersion time.

\subsection{Tafel and EIS Experiments Results}

Tafel and Nyquist plots of PPy coated samples were given Fig. 3. Tafel and plots of Ni + PPy coated samples were given Fig. 4.

Corrosion characteristics of $304 \mathrm{SS}$ in $1 \mathrm{~mol} \mathrm{dm}^{-3}$ $\mathrm{NaOH}$ solution different immersion time were given Table 1.

According to Table 1 and Fig. 3a the $i_{\text {corr }}$ value of uncoated steel surface appears to be quite high. This shows that steel surface is an unstable and iron in steel becoming quickly ion has suffered corrosion [31]. By the Gui and Devine [27] passivation of steel $\mathrm{Fe}(\mathrm{OH})_{2}$ and $\gamma-\mathrm{Fe}_{2} \mathrm{O}_{3} / \mathrm{Fe}_{3} \mathrm{O}_{4}$ defined by the formation of film.
By Nagayama and Cohen [35] such a complex structure was formed by merging the inner layer of $\mathrm{Fe}_{3} \mathrm{O}_{4}$ and outer layer of the $\mathrm{Fe}_{2} \mathrm{O}_{3}$. These oxides formation on steel surface cut off metal/solution contact closing of steel surface. Corrosion is reduced to the close of the oxide film surface. This oxide film is broken, broken area begins pit corrosion and $i_{\text {corr }}$ values increases again with time. The magnitude of the current due to the reactions occurring on the stainless steel substrate during the polarizations will depend on how much of the electrolyte can permeate through the porous of the PPy layer [29]. On the other hand, considering the positive applied potentials and the permeation of water through the polymer matrix, the passive oxide 
(a)
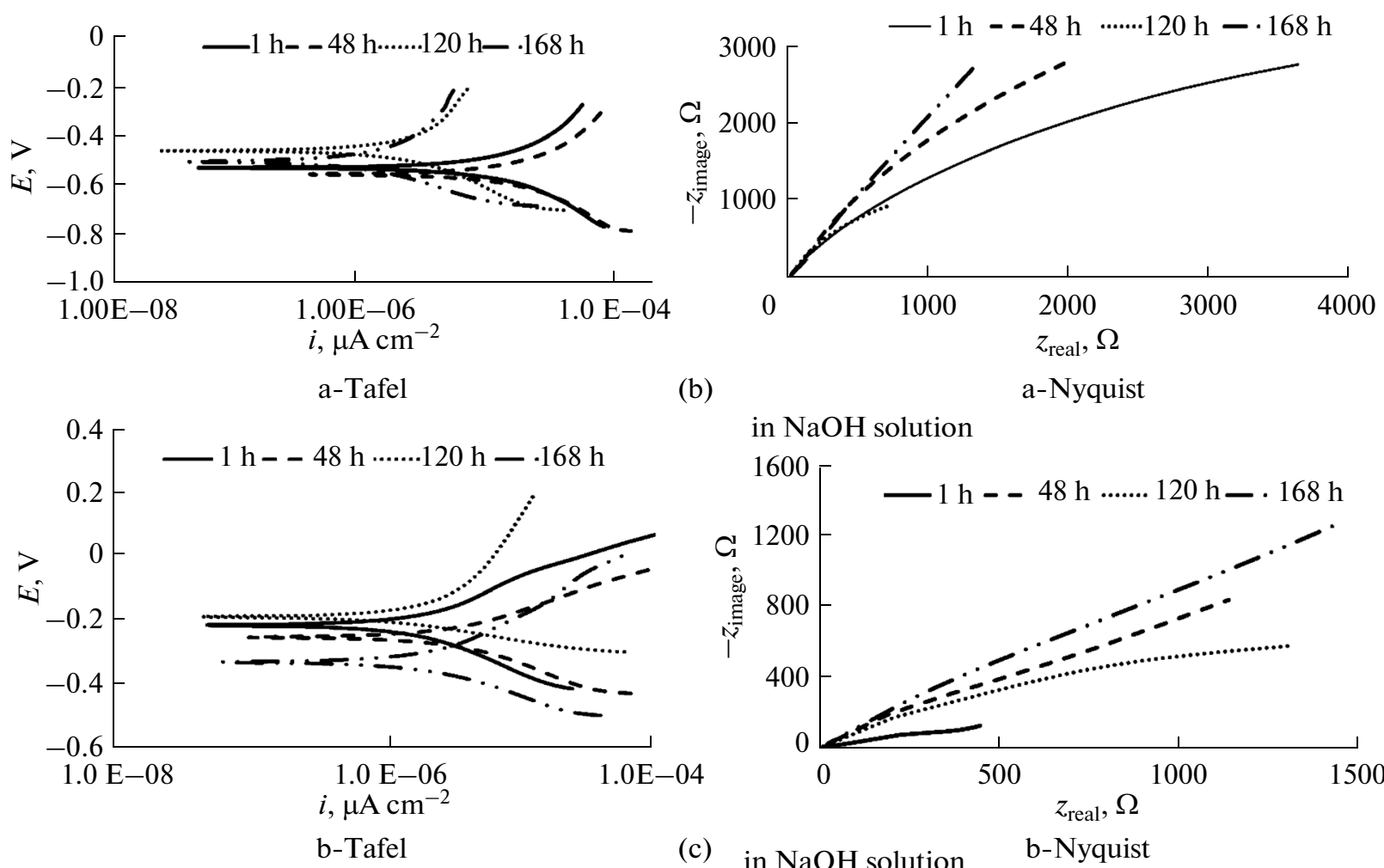

(b)

in $\mathrm{NaOH}$ solution

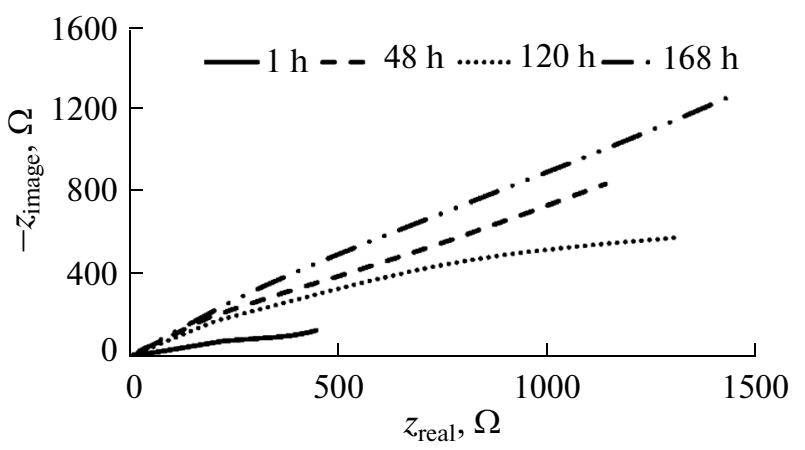

(c) in $\mathrm{NaOH}$ solution b-Nyquist
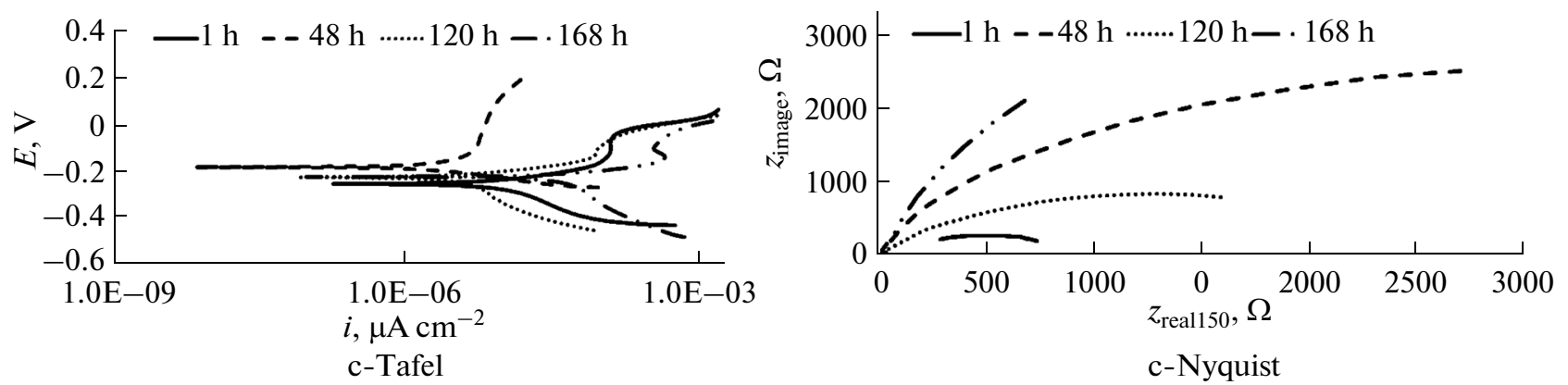

Fig. 4. Tafel and Nyquist plots of $\mathrm{Ni}+\mathrm{PPy}$ coated $304 \mathrm{SS}$ in $1 \mathrm{~mol} \mathrm{dm}^{-3} \mathrm{NaOH}, 0.5 \mathrm{~mol} \mathrm{dm}^{-3} \mathrm{H}_{2} \mathrm{SO}_{4}$ and $3.5 \%$ (wt/vol) $\mathrm{NaCl}$ solutions different immersion time.

film can be replenished by oxidation of the substrate, minimizing the rate of localized attack [30].

The result is interpreted taking also into account the stabilization of the oxide film by a substrate/polymer interaction at these positive potentials and over oxidation of the polymer [29]. According to literature data, the curves are characterized by the appearance of current peaks in the active and transpassive regions in both, nearly neutral [16] and alkaline [17] solutions. The first potential region is mainly related to the iron redox processes of $\mathrm{Fe} / \mathrm{Fe}(\mathrm{II})$ and $\mathrm{Fe}(\mathrm{II}) / \mathrm{Fe}_{3} \mathrm{O}_{4}$. At the most positive potentials the current density starts to increase again due to the processes of $\mathrm{Cr}(\mathrm{III}) / \mathrm{Cr}(\mathrm{VI})$ and $\mathrm{Ni}(\mathrm{II}) / \mathrm{Ni}(\mathrm{III})$. Oxygen evolution also contributes to the anodic current in this potential range. The cathodic waves observed during the reverse scan are ascribed to the electroreduction of $\mathrm{Cr}(\mathrm{VI})$ and $\mathrm{Fe}(\mathrm{III})$ species [5]. $i_{\text {corr }}$ values of PPy coated steel have decreased by up to $48 \mathrm{~h}$ (Table 1) and after than $i_{\text {corr }}$ values again increases. But according to uncoated corrosion rates of steels are quite small, inhibition percent changed from 46 to $36 \%$, PPy coating inhibited anodic dissolution of steel, $i_{\text {corr }}$ values in $1 \mathrm{~N} \mathrm{NaOH}$ solution lower than $\mathrm{NaCl}$ and $\mathrm{H}_{2} \mathrm{SO}_{4}$, because the steel surface is covered with oxides and hydroxides. Changing in $i_{\text {corr }}$ values are compatible with the Rp values. A passive film (Table 3) can not be formed on the surface of the electrode.

Corrosion potential of iron is decreased if a passive layer can not be built sufficiently redissolution of iron oxalates. A slight increase in the potential in this area indicates that the internal load changes between 
Table 1. Corrosion characteristics of $304 \mathrm{SS}$ in $1 \mathrm{~mol} \mathrm{dm}^{-3} \mathrm{NaOH}$ solution different immersion times

\begin{tabular}{|c|c|c|c|c|c|c|c|}
\hline & $\begin{array}{l}\text { Immersion } \\
\text { time, } h\end{array}$ & $\begin{array}{c}\beta a, \\
\mathrm{mV} / \text { decade }\end{array}$ & $\begin{array}{c}-\beta \mathrm{c} \\
\mathrm{mV} / \text { decade }\end{array}$ & $\begin{array}{c}i_{\text {corr }} \\
\mu \mathrm{A} / \mathrm{cm}^{2}\end{array}$ & $E_{\text {corr }}, \mathrm{mV}$ & $\begin{array}{l}\text { Corrosion } \\
\text { rate, mpy }\end{array}$ & $\begin{array}{l}\mathrm{R}_{\mathrm{p}} \\
\mathrm{k} \Omega\end{array}$ \\
\hline \multirow{6}{*}{ Uncoated } & 1 & 342 & 334 & 18.51 & -349 & 8.30 & 13.85 \\
\hline & 24 & 587 & 477 & 9.21 & -336 & 5.96 & 43.29 \\
\hline & 48 & 516 & 298 & 3.89 & -121 & 1.80 & 70.10 \\
\hline & 72 & 873 & 722 & 15.21 & -353 & 9.84 & 39.86 \\
\hline & 120 & 504 & 414 & 16.63 & -324 & 7.50 & 20.00 \\
\hline & 168 & 364 & 331 & 21.58 & -310 & 9.70 & 12.10 \\
\hline \multirow{6}{*}{ PPy coated } & 1 & 362 & 338 & 9.91 & -293 & 4.40 & 33.33 \\
\hline & 24 & 141 & 14.5 & 4.61 & -450 & 2.07 & 47.60 \\
\hline & 48 & 141 & 147 & 2.12 & -332 & 1.40 & 37.38 \\
\hline & 72 & 62 & 51 & 2.48 & -505 & 1.22 & 13.90 \\
\hline & 120 & 510 & 419 & 3.01 & -321 & 6.20 & 25.40 \\
\hline & 168 & 328 & 222 & 3.6 & -284 & 8.30 & 24.00 \\
\hline \multirow{6}{*}{$\begin{array}{l}\mathrm{Ni}+\mathrm{PPy} \\
\text { coated }\end{array}$} & 1 & 74.5 & 80 & 8.14 & -249 & 3.60 & 6.56 \\
\hline & 24 & 328 & 136 & 1.06 & -350 & 2.50 & 13.60 \\
\hline & 48 & 218 & 831 & 0.53 & -499 & 2.40 & 17.30 \\
\hline & 72 & 221 & 145 & 0.99 & -300 & 2.90 & 16.00 \\
\hline & 120 & 201 & 45 & 7.43 & -281 & 3.40 & 7.50 \\
\hline & 168 & 689 & 306 & 20.16 & -394 & 9.03 & 1.50 \\
\hline
\end{tabular}

oxalate and chloride ions. Cross linked polymers play the role of barrier. They hidden cathodic reactant transport. According to Riaz et al. [31] PPy coated steel showed that the passive layer from the initial immersed to solution. Charge transfer resistance increased for 5 days and $\mathrm{pH}$ of the electroylte decreased. These observations can be explained steel surface oxidation and in part reduction of the polymer.

As can be seen Table 3, Rp decreased over time. In $\mathrm{H}_{2} \mathrm{SO}_{4}$ solution, dissolution of iron is anodic reaction, reduction of hydrogen is cathodic reduction. On the other hand, products as a result of corrosion accumulate in the pores of film make it more diffucult permeability of film an increaese of film resistance. After 24, 48 and 72 hours waited, total resistance increased in $\mathrm{NaOH}$ solution (Table 1 and Figs. 3a, 3b) Nyquist plots of coating formed dielectric field. Concerned of a capacitive model, metal and solution behaved a paralel plates, the capacitive feature seems to have changed over time.

$E_{\text {corr }}$ potential of PPy coated steels more anodic potentials than bare steel. This is start of anodic passive film on steel under $E_{\text {corr }}$ characteristic values related to the PPy pores. Over time, the pores caused by the corrosion of steel in solutions until the fill in and dissolution of passive film $\left(\mathrm{FeC}_{2} \mathrm{O}_{4} \mathrm{H}_{2} \mathrm{O}\right)$ and $E_{\text {corr }}$ decreased [29].

For example dissolved oxygen ions can be transported towards or away from corrosion products of neutral medium (Table 2, Fig. 3b). Conductive poly- mers are expected reduction of corrosive ions such as $\mathrm{Cl}^{-}$inside entering film. This suggests that the coatings are effective barriers to the inward diffusion of $\mathrm{Cl}^{-}$ ions, and thus inhibit the corrosion of the substrate alloy.

The theory clearly shows the importance of oxygen reduction reaction of the polymer surface. This system offers several unique advantages. Imperfection in the coating like pinholes, accidental scratches, crevices are often difficult to avoid. They are responsible for corrosion initiation in most of the cases. Since the potential of the whole surface is the same when protecting by catalyzed conducting polymer, partial exposure due to coating imperfections will not initiate corrosion. In addition, this type of coating can be used as an efficient primer coat to be applied under top coat of commercial paint.

Adherent films of polypyrrole and other conductive polymers have been demonstrated to raise the potential of steel in the passive region at the immersion to provide anodic protection. Electropolymerization of pyrole on steel surface has been a subject of great interest. The deposition competes with the dissolution of iron [25]. Initially, PPy film is passive, but over time to be active and corrosion rate is increased.

If a conductive polymer is an insulator, electrochemically is undoped. It is expected to act as a barrier. Because it is weak in both electronic and ionic conducting. As an insulator polymer advantage of conductive polymer can be form a thick polymer film 
Table 2. Corrosion characteristics of $304 \mathrm{SS}$ in $3.5 \%$ (wt/vol) $\mathrm{NaCl}$ solution different immersion times

\begin{tabular}{|c|c|c|c|c|c|c|c|}
\hline & $\begin{array}{c}\text { Immersion } \\
\text { time, } h\end{array}$ & $\begin{array}{c}\beta a, \\
\mathrm{mV} / \mathrm{dec} \text { ade }\end{array}$ & $\begin{array}{c}-\beta \mathrm{c}, \\
\mathrm{mV} / \mathrm{dec} \text { ade }\end{array}$ & $\begin{array}{c}i_{\text {corr }}, \\
\mu \mathrm{A} / \mathrm{cm}^{2}\end{array}$ & $E_{\text {corr }}, \mathrm{mV}$ & $\begin{array}{l}\text { Corrosion } \\
\text { rate, mpy }\end{array}$ & $\mathrm{Rp}, \mathrm{k} \Omega$ \\
\hline \multirow{6}{*}{ Uncoated } & 1 & 512 & 236 & 9.55 & -208 & 1.50 & 76.48 \\
\hline & 24 & 158 & 188 & 1.07 & -238 & 2.74 & 18.94 \\
\hline & 48 & 257 & 198 & 3.89 & -429 & 1.10 & 41.56 \\
\hline & 72 & 258 & 111 & 1.35 & -263 & 3.09 & 30.10 \\
\hline & 120 & 282 & 143 & 4.95 & -340 & 1.70 & 22.00 \\
\hline & 168 & 193 & 28.1 & 8.49 & -380 & 3.20 & 3.86 \\
\hline \multirow{6}{*}{ PPy coated } & 1 & 237 & 197 & 24.12 & -144 & 11.30 & 6.30 \\
\hline & 24 & 193 & 109 & 12.63 & -243 & 5.60 & 7.20 \\
\hline & 48 & 282 & 78 & 23.71 & -311 & 10.90 & 3.60 \\
\hline & 72 & 302 & 140 & 16.28 & -259 & 7.30 & 6.50 \\
\hline & 120 & 416 & 144 & 32.91 & -233 & 14.50 & 2.20 \\
\hline & 168 & 698 & 50.5 & 34.68 & -202 & 15.60 & 1.80 \\
\hline \multirow{6}{*}{$\begin{array}{c}\mathrm{Ni}+\mathrm{PPy} \\
\text { coated }\end{array}$} & 1 & 225 & 56 & 34.32 & -305 & 15.50 & 1.80 \\
\hline & 24 & 190 & 155 & 16.63 & -259 & 6.90 & 8.20 \\
\hline & 48 & 296 & 267 & 21.23 & -253 & 7.60 & 8.37 \\
\hline & 72 & 200 & 231 & 20.52 & -279 & 7.60 & 7.20 \\
\hline & 120 & 255 & 80 & 56.26 & -400 & 25.29 & 7.50 \\
\hline & 168 & 111 & 337 & 71.83 & -309 & 32.29 & 5.58 \\
\hline
\end{tabular}

using electropolymerization method. If the polymer film is conductive or supported (doped) as electrochemically acts as an efficient way to oxidizing in the field of passivity whole examined conductive polymer are $\mathrm{p}$-doped polymer and therefore provide galvanic protection. Oxidation of pyrrole usually stars around $0.23 \mathrm{~V} \mathrm{SCE}$. For this reason, passive film on metal must occur before PPy film growth.

Low-resolution ferrous oxalate consists of approximately $-0.65 \mathrm{~V} \mathrm{SCE}$. More noble potential values show that the film has ability to repair itself. This indicates that the damaged places again really repassivation. The film on surface should have a good conductivity for faster transfer of electrons from the surface of the metal. This is protective ferrous oxalate film. Oxalate anions supports fast moving towards to the same site. The mechanism of protection in various aqueous corrosive environments of polymers composed of several steps. Polymer coating and solution consist of the redox process, coated electrodes submerged in corrosive solution. In this step, in solution between $\mathrm{Cl}^{-}$and oxalate ions occur change and charge transfer resistance exhibit slow values. In the meantime, $\mathrm{Cl}^{-}$concentration of surface increase and active corrosion occurs and the charge transfer resistance continues increase. The observed process the formation of insoluble iron oxalate complex metal polymer interface is inhibited temporarily. Finally the iron corrosion resistance increases with decreasing charge transfer rate [19]. Assuming that after prolonged expo- sure times, most of the oxalate anions dedoping was finished. During time, the overall impedance increases steel. It should be pointed out that during time the real part of the impedance at high frequencies, which could be connected with the ohmic resistances of the system increases as well [31].

Current values of coated electrodes are lower than compared to the uncoated electrodes. PPy and $\mathrm{Ni}+$ PPy coatings on the surface slowed down anodic dissolution of metal showing the effect of a barrier. Surface of stainless steels is covered with stable of Cr(III), $\mathrm{Fe}$ (III) and Ni oxide layers. These layers provides a protective effect of metal. However coatings have certain amount of porosities such as $\mathrm{Cl}^{-}$diffuse pitting corrosion of metal surface at certain points in time, and thus cause degredation of the metal (Table 2 and Fig. 3b) available as a quality second layer on the surface (homogenous and well-sticking surface) is a conductive polymer film acting as a barrier to minimize contact with the steel surface of solutions slow down the corrosion rate. Nyquist diagrams of $\mathrm{Ni}+\mathrm{PPy}$ and PPy coatings increasing resistance of medium frequency as a result of plogging of pores is associated with the increase in pore resistance, polymer occurs as a result of open pores formed protective oxide products (Fe(III) oxide). On a result of pores increases corrosion rate over time.

Figure 4 are also given anodic polarization curves of anodic polarization curves of uncoated electrode, PPy coated, $\mathrm{Ni}+$ PPy coated in $1 \mathrm{~mol} \mathrm{dm}^{-3} \mathrm{NaOH}$, 
Table 3. Corrosion characteristics of $304 \mathrm{SS}$ in $0.5 \mathrm{~mol} \mathrm{dm}{ }^{-3} \mathrm{H}_{2} \mathrm{SO}_{4}$ solution different immersion times

\begin{tabular}{c|c|c|c|c|c|c|c}
\hline & $\begin{array}{c}\text { Immersion } \\
\text { time, } \mathrm{h}\end{array}$ & $\begin{array}{c}\beta \mathrm{a}, \\
\mathrm{mV} / \mathrm{dec}\end{array}$ & $\begin{array}{c}-\beta \mathrm{c}, \\
\mathrm{mV} / \mathrm{dec} \text { ade }\end{array}$ & $i_{\text {corr }} \mu \mathrm{A} / \mathrm{cm}^{2}$ & $E_{\text {corr }}, \mathrm{mV}$ & $\begin{array}{c}\text { Corrosion } \\
\text { rate, mpy }\end{array}$ & $R_{\mathrm{p}}, \mathrm{k} \Omega$ \\
\hline \multirow{5}{*}{ Uncoated } & 1 & 610 & 120 & 23.53 & -129 & 10.58 & 6.03 \\
& 24 & 322 & 434 & 4.40 & -120 & 13.18 & 50.02 \\
& 48 & 579 & 310 & 61.57 & -109 & 27.70 & 4.98 \\
& 12 & 270 & 289 & 13.18 & 140 & 30.17 & 7.60 \\
& 120 & 118 & 427 & 92.35 & -102 & 41.40 & 23.80 \\
& 168 & 408 & 30 & 106.86 & -136 & 48.10 & 0.34 \\
\hline \multirow{5}{*}{ PPy coated } & 1 & 261 & 63 & 60.16 & -41 & 28.50 & 5.22 \\
& 24 & 276 & 23 & 63.69 & 11 & 28.70 & 0.90 \\
& 48 & 372 & 35 & 63.88 & -85 & 30.10 & 0.70 \\
& 12 & 260 & 26 & 67.23 & 43 & 30.2 & 0.40 \\
& 16 & 234 & 30 & 26.3 & -116 & 41.80 & 0.30 \\
& 1 & 282 & 489 & 38.0 & -135 & 61.00 & 1.28 \\
\hline \multirow{5}{*}{ Ni+PPy } & 24 & 46 & 181 & 7.85 & -199 & 3.50 & 8.82 \\
& 48 & 201 & 89 & 7.96 & -71 & 3.60 & 7.10 \\
& 72 & 88 & 185 & 16.28 & -107 & 8.30 & 7.87 \\
& 120 & 65 & 666 & 19.49 & -218 & 8.70 & 5.60 \\
& 168 & 120 & 48 & 47.77 & -202 & 21.50 & 0.80 \\
\hline
\end{tabular}

$1 \mathrm{~mol} \mathrm{dm}^{-3} \mathrm{NaCl}$ and $0.5 \mathrm{~mol} \mathrm{dm}{ }^{-3} \mathrm{H}_{2} \mathrm{SO}_{4}$ solutions. Nickel and chromium oxide film on the surface of uncoated electrode show passivity, but porous structure of oxides begins to dissolve quickly with diffusion of $\mathrm{Cl}^{-}$ions.

During the same time electrolyte fills in the pores and reacts with the passive layer at the bottom of the PPy pores. Dissolution of iron through pores occurs, provoking the decrease of open circuit potential near to the values of bare steel electrode. After that time, the anodic reaction (dissolution of iron through the pores) and main cathodic reaction (hydrogen evolution reaction on PPy surfaces) are controlled by diffusion kinetics of PPy reduction. Dedoping of oxalate anions from the bulk of the polymer decreases the polymer conductivity which provokes the decrease of the overall corrosion rate. The aging of the polymercovered 304 SS in sulfuric acid (Table 3, Fig. 3c) makes the steel passive for a long time and this enhances the stability of oxide film underneath the polymer [30]. As seen, the potential of the uncoated electrode (Fig. $3 \mathrm{c}$ ) shifts towards less negative values in the first seconds of immersion. This indicates the formation of a passive oxide film on the alloy surface $[3,29]$.

Stable passive film under polypyrrole prolonged anodic polarization of $304 \mathrm{SS}$ in $\mathrm{H}_{2} \mathrm{SO}_{4}$ was found to induce better protective properties of the surface oxide films and better resistance to pitting. These properties are related to transformation of the passive layer with time by increasing of chromium oxide in the inner part which is responsible for maintaining passivity of stainless steel [22, 23, 26, 27]. Iron and nickel dissolve from the steel alloy surface in the early stage of anodic passivation and their flux from the oxide are substantial and almost entirely accounts for the residual passivation current [26, 27]. This decreases the content of these elements in the surface oxides especially at higher acid concentration and longer immersion time. The considerable amount of iron and nickel in the film under PPy, in the same condition of aging, indicates a lower dissolution rate of these species. Another significant difference in the chemical composition between the two oxides under investigation is the higher content of the bound water molecules and sulfate ions in the anodically passive oxides than in the oxides underneath PPy. This indicates the higher hydration of the anodically formed oxides, which decreases their stability. In addition to the selective dissolution at the early stage of anodic passivation the surface oxides undergo some dissolution with aging. The residual passivation current density, where the anodic current drops to a lower value, represents an equilibrium state between the dissolution and film formation kinetics. Also, a breakdown and repassivation may occur during the polarization [26]. These dissolution processes on the surface lead to depletion of some constituents of the oxides like iron oxide and relatively lowering of chromium component, the main constituent of passivation. The passive oxides formed under PPy are 


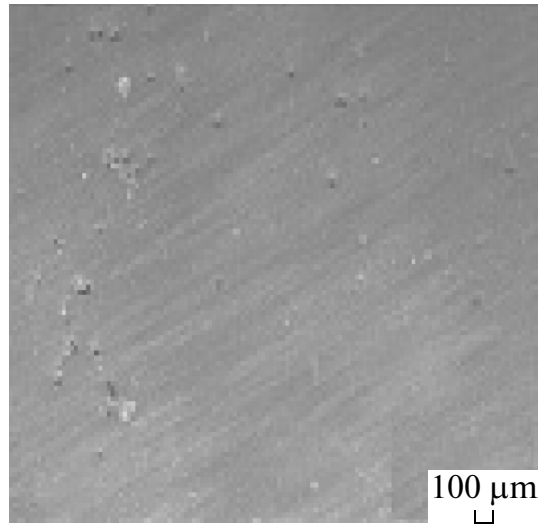

(a) uncoated

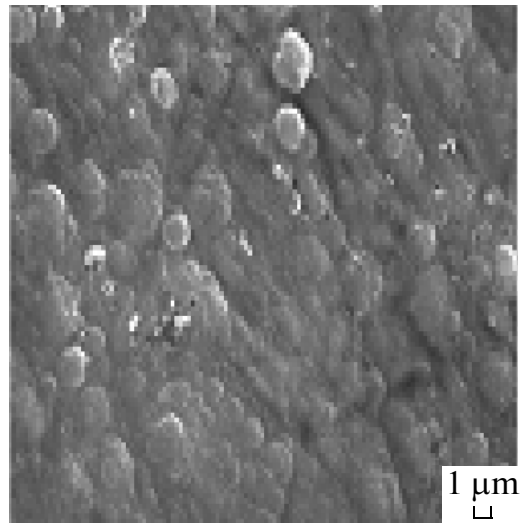

(b) PPy coated

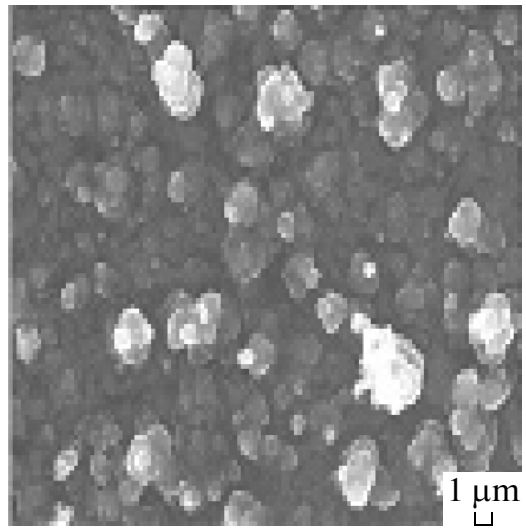

(c) $\mathrm{PPy}+\mathrm{SE}$ coated

Fig. 5. SEM micrographs of 304 SS.

mostly protected against the dissolution processes. The selective dissolution of some constituents from the alloy surface may be not significant in the film formation under the PPy. It is suggested that the initial passivation process under PPy is different than that by external applied potential. The sulfate ion is consumed as a dopant in the formation of PPy film and the oxidation of stainless steel is achieved under the environment of lower concentration of water and sulfate ions (Table 3). The rich chromium oxide film under PPy may be result by direct reaction of $\mathrm{Cr}$ with water to form $\mathrm{Cr}_{2} \mathrm{O}_{3}$ and then $\mathrm{Cr}(\mathrm{OH})_{3}$. These corrosion-resisting oxides are characterized by low hydroxides and sulfates. Further data are necessary to discuss the exact mechanism by which the Cr-rich film formed under conductive polymer, and which may provide more insight on the complex passivation process of stainless steels.

Visual inspection of the steel panels submitted to corrosion cycles indicates that the resistance against corrosion of the corrosion protection of metal-rich coatings relies on the electrical communication between these active metals with the underlying metal, forming a galvanic pair, where the zinc $(\mathrm{Cr}$ or $\mathrm{Mg})$ acts as sacrificial anode (cathodic protection) [30].

Galvanic interaction between the metallic substrate and the coating is the most postulated reason for corrosion protection imparted by conducting polymers [28]. The polymer has the ability to oxidize the metal to form a passive film [29]. This and other proposed mechanisms to be operative require the coating to be in the conductive state [5].

The Ni + PPy coating is slightly more positive than PPy because the porous layer of PPy becomes compacted when Ni are embedded in the polymer decreasing the porosity and forming strong barrier to external agents. In general, the properties of PPy are strongly dependent on polymerization conditions such as, the type of dopant used, the concentrations of pyrrole and the dopant, the applied voltage, the solvent, and reaction temperature [15].

Oxide film on the surface of uncoated electrode soluble around $0.45 \mathrm{~V}$. Polymer film coated electrodes formed due to the catalytic effect of the protective effect of the barrier oxide film shows the current values of this potential is lower than that of the uncoated electrode. In addition $\mathrm{SO}_{4}^{2-}$ ions are larger than $\mathrm{Cl}^{-}$ ions are more diffucult diffusions. Therefore, the formation of oxide is slower than $\mathrm{Cl}^{-}$environment and depending on the oxide film resistance values of $\mathrm{SO}_{4}^{2-}$ environment are smaller than resistance values of $\mathrm{Cl}^{-}$ environment (Tables 2 and 3) minimized anodic dissolution of the metal coating. In addition $E_{\text {corr }}$ values of this coating around $-499 \mathrm{mV}$. In particular this value appears to be very cathodic electrode potential. This Ni + PPy coated electrode a good barrier effect against corrosion of steel than other covers and corrosion rate of metal shows slowing down. Corrosion rates of PPy coated are greater than $\mathrm{Ni}+$ PPy coated electrodes (Figs. 3, 4 and Tables 1-3). Currents belong to polarisation plots or cathodic direction are greater than currents belong to polarization plots of anodic direction. From this point, during the coating the surface are not completely covered and anodic dissolution occured. Depending on the redox properties of conductive polymer, the conductivity is changed and coated metal is known to protect the metal from corrosion.

Oxidated conductive polymer in corrosive environment and decreasing conductivity of the polymer is reduced to take metal electrons from all over the metal and is ready, for rebuffering all over the corrosive effects of the environment. PPy inhibited anodic dissolution of steel in $\mathrm{NaOH}$ and $\mathrm{H}_{2} \mathrm{SO}_{4}$. Tafel and Nyquist plots $\mathrm{Ni}+$ PPy coated $304 \mathrm{SS}$ are given Fig. 4 at different waiting time in $1 \mathrm{~N} \mathrm{H}_{2} \mathrm{SO}_{4}, 3.5 \%$ (wt/vol) $\mathrm{NaCl}$ and $1 \mathrm{~N} \mathrm{NaOH}$ solutions. Table $1 \mathrm{Ni}+\mathrm{PPy}$ 
coated 304 SS showed better corrosion resistance than PPy coated and uncoated 304 SS. The best inhibiton was observed PPy and Ni + PPy coated 304 SS immersion for $72 \mathrm{~h}$.

$\mathrm{Ni}+$ PPy coated $304 \mathrm{SS}$ was seen $93 \%$ inhibition. $\mathrm{NaOH}$ solution contribute to the inhibition (Table 1). Pyrrole attached to surface via the enriched delocalized electrons and - NH group. Adsorption on the surface occurs as physically and weak bonds. Table 2, $\mathrm{Ni}+\mathrm{PPy}$ coated $304 \mathrm{SS}$ showed better corrosion resistance compared to uncoated and PPy coated 304 SS. The best corrosion inhibition calculated $86 \%$ inhibition waited 48 hours environment. $E_{\text {corr }}$ values shifted to more positive potentials $(\mathrm{Ni}+$ PPy coated samples except 120 and $168 \mathrm{~h}$ ).

\subsection{SEM Analysis}

SEM micrographs of uncoated, polypyrrole coated and $\mathrm{NaOH}$ pretreatment polypyrrole $+\mathbf{S E}$ coated steels is given Fig. 5. As can be seen in Fig. 5a, there are grinding errors on the surface of bare steel. Figure $5 b$ shows the surface is coated with polypyrrole. Polypyrrole in the form of spheres coated on the surface. Figure $5 \mathrm{c}$ polypyrrole coated steel surface formed a good film. It is observed spheres grew on the surface. Ferrous oxalate crystals are orthorhombic structure. As it can be seen, a uniform globular type spheroidal morphology is observable all over the surface. The PPy films are compact and very homogeneous. Their surface is characterized by a cauliflower-like structure constituted by microspherical grains and clusters of globules. Also, it has been shown that homogeneous and regular polymer surface becomes more and more granular as the thickness increases. The PPy surface morphology, however, is affected by polyphosphate concentration. As polyphosphate is a surfactant, then very smooth, compact, and flexible.

\subsection{FTIR Analysis}

FTIR spectrums of uncoated, PPy coated and $\mathrm{NaOH}$ pretreatment PPy + SE coated of 304 SS are given Fig. 6.

Spectrums can be interpreted (a) uncoated: $3407 \mathrm{~cm}^{-1}$ $\mathrm{N}-\mathrm{H}$ tension band, $1142 \mathrm{~cm}^{-1}$ : $\mathrm{C}-\mathrm{N}$ tension band, (b) PPy coated: $3446.03 \mathrm{~cm}^{-1} \mathrm{~N}-\mathrm{H}$ tension band, 3026-2926 $\mathrm{cm}^{-1}$ aromatik, $\mathrm{C}-\mathrm{H}$ tension band, $1068 \mathrm{~cm}^{-1}$ : C-N tension, (c) PPy + SE: N-H tension band $3437 \mathrm{~cm}^{-1}, \mathrm{C}=\mathrm{C}$ tension band $1683 \mathrm{~cm}^{-1}, \mathrm{C}-\mathrm{N}$ tension band $1259 \mathrm{~cm}^{-1}$.

\section{CONCLUSIONS}

1. $304 \mathrm{SS}$ has a wide range of passivity in oxalic acid solution. This supports the formation of polypyrrole.

2. SEM images show that surface coated by polypyrrole in the form of spheres coated on the surface.

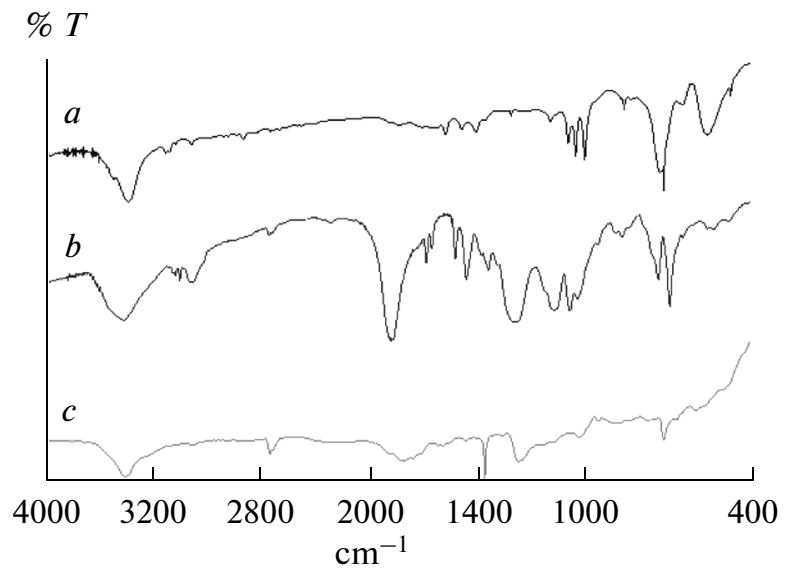

Fig. 6. FTIR spectrums of 304 SS surface $(a)$ uncoated, $(b)$ PPy coated, (c) PPy + SE coated.

3. FTIR analysis shows characteristics absorption bands of pyrrole.

4. PPy coating and $\mathrm{Ni}+\mathrm{PPy}$ coating prevented corrosion in $\mathrm{NaOH}$ and $\mathrm{H}_{2} \mathrm{SO}_{4}$ solution. Corrosion rate decreases up to $48 \mathrm{~h}$ in $\mathrm{NaCl}$ and $\mathrm{H}_{2} \mathrm{SO}_{4}$ solution, then increase again corrosion of metal with time.

5. Ni + PPy coatings showed better corrosion resistance than PPy coatings, these resistances change with $i_{\text {corr }}$ values.

6. Corrosion rates increase owing to pitting in $\mathrm{NaCl}$ solution.

\section{ACKNOWLEDGMENTS}

The authors thank the Scientific Research Project Council of Afyon Kocatepe University for their support of this project (Project Number: 07.FENED.22).

\section{REFERENCES}

1. Su, W. and Iroh, J.O., Electrochim. Acta, 1999, vol. 44, p. 4655.

2. Mabrouk, P.A., Synthetic Metals, 2005, vol. 150, p. 101.

3. Kabasakaloglu, M., Kiyak, T., Şendil, O., and Asan, A., Appl. Surf. Sci., 2002, vol. 193, p. 167.

4. Özyilmaz, A.T., Kardas, G., Erbil, M., and Yazıcı, B., Appl. Surf. Sci., 2005, vol. 242, p. 97.

5. Nguyen, T.L., Le, H., Garcia, B., et al., Electrochim. Acta, 2001, vol. 46, p. 4259.

6. Su, W. and Iroh, J.O., Electrochim. Acta, 2000, vol. 46, p. 1.

7. Zhu, R., Li, G., and Huang, G., Materials and Corrosion, 2009, vol. 60, p. 34.

8. Kumar, D., Synthetic Metals, 2000, vol. 114, p. 369.

9. Giacomini, M.T., de Souza, L.M.M., and Ticianelli, E.A., Surface Sci., 1998, vol. 409, p. 465.

10. Krstajic, N.V., Grgur, B.N., Jovanovic, S.M., and Vojnovic, M.V., Electrochim. Acta, 1997, vol. 42, p. 1685. 
11. Bader, H., Ringsdorf, H., and Schmidt, B., Macromoleculer Materials and Engineering, 1984, vol. 123, p. 457.

12. Geetha, S., Chepuri, R., Vijayan, M., and Trivedi, D., Analyt. Chim. Acta, 2006, vol. 568, p. 119.

13. Johanson, U., Marandi, M., Tamm, T., and Tamm, J., Electrochim. Acta, 2005, vol. 50, p. 1523.

14. Herrasti, P., Diaz, L., Ocón, P., et al., Electrochim. Acta, 2004, vol. 49, p. 3693.

15. Rahman, S.U. and Ba-Shammakh, M.S., Synthetic Metals, 2004, vol. 140, p. 207.

16. Shao, Y., Jin, Y., Wang, J., et al., Biosensors and Bioelectronics, 2005, vol. 20, p. 1373.

17. Martins, J.I., Bazzaoui, M., Reis, T.C., et al., Progress in Organic Coatings, 2009, vol. 65, p. 62.

18. Giacomini, M.T., de Souza, L.M.M., and Ticianelli, E.A., Surface Sci., 1998, vol. 409, p. 465.

19. Yagan, A., Pekmez, N.Ö., and Yildiz, A., Progress in Organic Coatings, 2007, vol. 59, p. 297.

20. Sabouria, M., Shahrabia, T., Faridi, H.R., and Hosseini, M.G., Progress in Organic Coatings, 2009, vol. 64, p. 429.

21. Attarzadeh, N., Raeissi, K., and Golozar, M.A., Progress in Organic Coatings, 2008, vol. 63, p. 167.

22. Ashrafi, A., Golozar, M.A., and Mallakpour, S., Synthetic Metals, 2006, vol. 156, p. 1280.

23. Gao, Y., Zhao, L., Bai, H., et al., J. Electroanal. Chem., 2006, vol. 597, p. 13.
24. Orhan, A. and Buytoz, S., Science and Eng., 2007, vol. 19, p. 593.

25. Bazzaoui, M., Martins, M., Costa, S., et al., Electrochim. Acta, 2006, vol. 51, p. 4516.

26. Machnikov, E., Pazderov, M., Bazzaoui, M., and Hackerman, N., Surface and Coatings Technology, 2008, vol. 202, p. 1543.

27. Gui, J. and Devine, T.M., Corrosion Sci., 1994, vol. 36, p. 441.

28. Okamoto, G., Nagayama, M., Kato, J., and Baba, T., Corrosion Sci., 1962, vol. 2, p. 21.

29. Bereket, G. and Hür, E., Progress in Organic Coatings, 2009, vol. 65, p. 116.

30. Grgur, B.N., Zivkovic, P., and Gvozdenovic, M.M., Progress in Organic Coatings, vol. 56, p. 240.

31. Riaz, U., Ashraf, S.M., Ahmad, S., Progress in Organic Coatings, 2007, vol. 59, p. 138.

32. Reut, J., Öpik, A., and Idla, K., Synthetic Metals, 1999, vol. 102, p. 1392.

33. Machnikova, E., Pazderova, M., Bazzaoui, M., and Hackerman, N., Surface and Coatings Technology, 2008, vol. 202, p. 1543.

34. Wang, L.X., Li, X.G., and Yang, Y.L., Reactive and Functional Polymers, 2001, vol. 47, p. 125.

35. Nagayama, M. and Cohen, M.J., Electrochem. Soc., 1962, vol. 109, p. 781. 